\title{
Teaching ABC \& Cost Behaviors To Non-Numbers People
}

Virginia Anne Taylor, (E-mail: TaylorV@wpunj.edu), William Paterson University Martin Rudnick, (E-mail: Rudnickm@wpunj.edu), William Paterson University

\begin{abstract}
Simply put, a cost analysis studies how you spend your money. Activity based costing models associate costs with services and cost benefit analysis weighs whether or not the costs expended were worth the money given the efforts involved and the results achieved. This study seeks to understand the financial choices and information seeking behaviors of managers in the nonprofit world.
\end{abstract}

\section{INTRODUCTION}

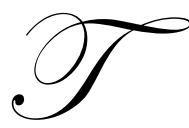

he first section presents an overview of public service organizational values. The next section a rationale and introduction to activity-based costing techniques explains why understanding your ABCs can give you a better understanding of your organization's operational processes and underlying expenses. In the final section will illustrate teaching examples specific to a non-profit organizations. A series of cost behavior charts and exercises illustrate cost behavior patterns in an information services environment. A hospital cost analysis exercise demonstrates steps in the allocation process.

\section{BACKGROUND \& VALUES}

Everyone decides how to spend or not spend the money in his or her personal bank accounts. These decisions are based on personal values. Professional groups are no different (Shera, 1976). Not-for profit organizations worldwide share some common values and these belief structures influence their use of money. Values often transcend national borders and the economic development levels of a particular country. Because these beliefs have been part of the professional culture for centuries they are almost unquestioned and unexamined. The beliefs influence all aspects of the management and are reflected in the choices about how to spend their money. These beliefs may include an expectation of being supported as a public good, a belief that growth is necessary and that their service matters the most, and the conviction that professional standards define public needs well. These values influence how non-profit organizations relate to financial issues, especially issues that address the construction of budgets. Because belief structures are so pervasive it is quite difficult to change currently used budgeting strategies quickly. Schools, hospitals, police departments, and librarians like spending money on these things and feel that doing so is a public service, one that is so self-evident there should be no need to explain why they always need more money. There is a deep-seated belief in all public service non-profit agencies that money is a major factor in success and that more money means more success (Taylor \& Coughlin, 2000). They believe that because they serve the public good it is good to give them money because, of course, they will do good things with the money. Most public servants feel they are very honest and trustworthy and can be allowed to spend money without a lot of outside control.

\section{RATIONALE FOR ABC}

The two big budget questions to answer are: what has been believed to be important about public sector spending over the last hundred years and what can one do better when spending money in the next hundred years. To answer these questions we must first look at the history of public services and money. It is a reasonably simple and universal history. Agencies usually ask for additional personnel and modern equipment to provide better programs 
and services and expanded facilities to serve more people. Surely these are worthy goals. We are often asked to vote "yes " for better schools, improved health care, more athletic fields, libraries, parks and open spaces. Historical precedent and professional recommendations are the two common approaches public administrators have employed as budget models. Planning models are developed based on growth goals and objectives. Public service agencies believe facilities, programs and services need to grow over time. If these public servants were argumentative they might say, if a park, hospital or school is good, more open space, recreation fields, libraries, classrooms or hospital services would be better. Another deep-seated belief is that they save individuals a great deal of money by providing patrons with tax supported services rather than expecting them to spend their money on buying more expensive individual private services. Most importantly, they believe the police, recreation, hospital and school facilities and services can enrich and even save lives and change the direction of a society.

However, as individuals with finite incomes we do the work of cost analysis and cost benefit analysis for ourselves on a very regular basis; and we use the results as we make economic decisions that guide our lives. Some are small decisions. Should we walk, take public transportation or drive to work? Each has a cost in time and each also has a monetary cost, even one as small as shoe repair bills. Some are large. Should we go to university for an advanced degree and forgo income for several years in the hope we will earn more money later? Should we have a large or small wedding? Should we buy a house and if so, how can we pay for it? Once you see just how often you do the work of cost analysis on a personal level, you may be surprised to recognize that this kind of work is not typically part of public service budgeting work. For all of the belief reasons mentioned above, they tend to skip this step and go straight to the people in charge and just ask for money for one or more good library needs. When you think about it a little longer, you may begin to be a bit chagrined and think that school or library requests for funds are a bit like children asking for ice cream on a hot summer day- a sweet, simple and unplanned act of begging. But the important agencies are not childlike and should not want to be compared to them when it comes to the important act of gathering and expending financial resources.

\section{INTRODUCTION TO ABC}

Activity based costing models identify activity centers within the organization and assigns costs to products and services based on events involved in the process of providing these products or services. Understanding your ABCs can give you a better understanding of your organization's operational processes and underlying expenses. It can uncover many hidden costs associated with providing services to allow managers to review the true cost when making decisions. The first concept to investigate is cost behavior analysis to uncover the true nature of the relationship between different kinds of costs and activity volume. The most basic breakdown of cost behavior is between fixed cost behavior and variable cost behavior. The total amount of a fixed cost will not change when activity levels go up or down. To understand the first chart think about your rent payment which remains the same each month regardless of the number of nights you are sleeping there. This is an example of a truly fixed cost; it has no relationship to the volume of activity. On the other hand, the total cost of a hotel bill will probably vary in direct proportion to the number of days you use the room. This is an example of a strictly variable cost that has a direct linear relationship to the volume of activity. Figure I shows charts to illustrate each of these two basic examples.

The third diagram represents a fairly simple mixed cost diagram. To understand the mixed cost, think about telephone service that covers a set number of minutes for a flat monthly fee (the fixed portion of the mix) and then adds a per minute charge for additional minutes used (the variable portion of the mix). For each example on the above chart the cost is shown on the vertical axis and the volume is shown on the horizontal axis. These three cost types can be expanded to develop a much larger "Match the Diagram: Cost Behavior and Information Services Exercise", an assignment that provides different examples of cost behaviors commonly found in libraries. It could use examples from any other institution. Each of the descriptions below meets the conditions of one of the charts detailing a type of cost behavior. In this exercise students are asked to select the chart that applies in each case. One could also ask students to estimate the total cost for a given period and illustrate it on the appropriate chart. 


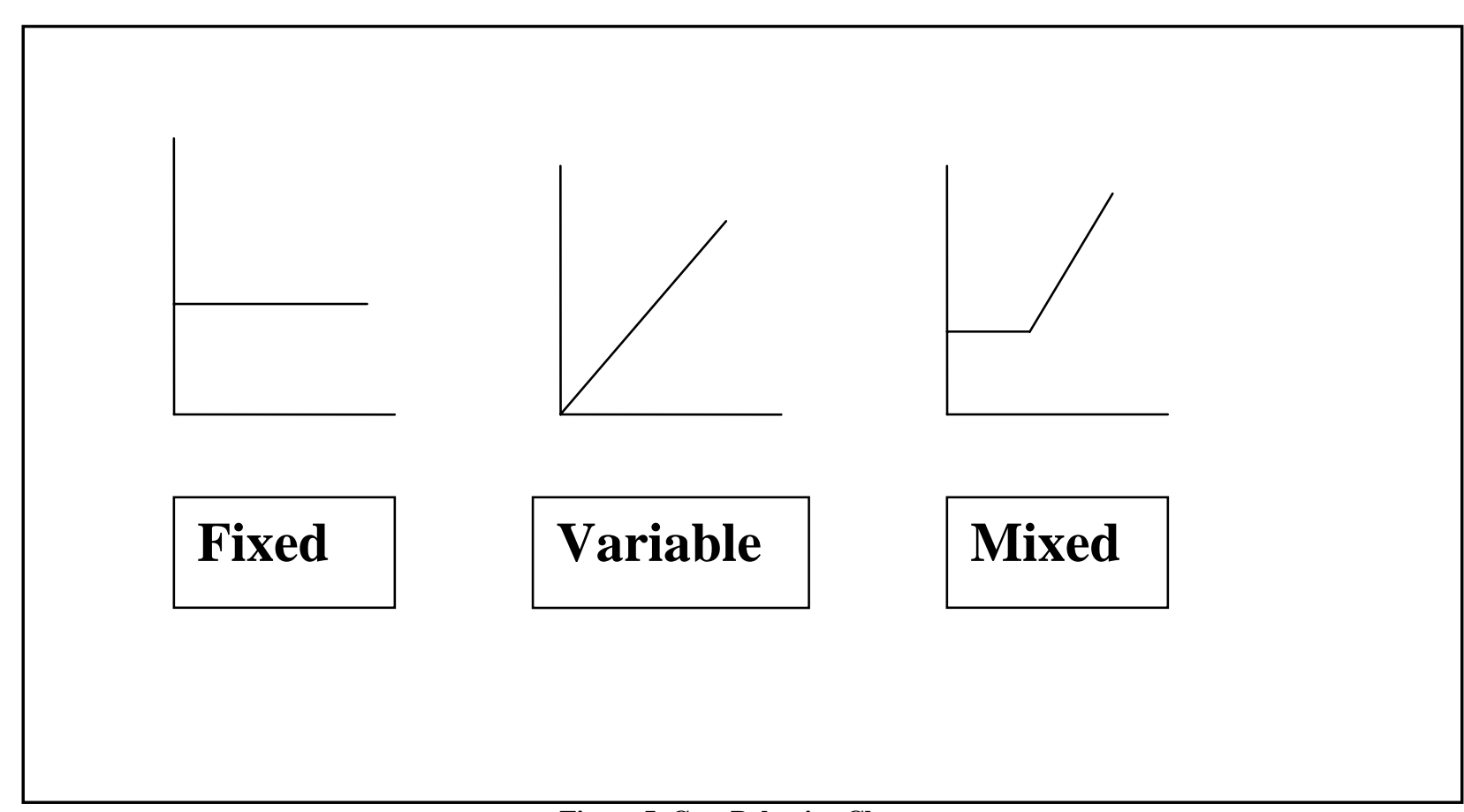

Figure I Cost Behavior Charts

\section{ADDITIONAL COST EXAMPLES}

1. The copy machine company charges us a rental fee is $\$ 30$ a month plus $\$ .04$ per copy.

2. Staples charges the school library $\$ 4$ per 1000 sheets of copy paper.

3. We charge students $\$ .05$ per copy.

4. $\quad$ Faculty pay $\$ 2.00$ a month for unlimited copy machine use.

5. $\quad$ For students who take less than twelve credit, tuition cost is $\$ 444$ per credit.

6. Students who register for twelve to eighteen credits pay \$ 5, 328

7. Students who take more than eighteen credits pay $\$ 5.328$ plus $\$ 444$ per credit.

\section{SUMMARY}

These principles are applicable to many types of departments or institutions. A pilot study is a good way to begin. The first step would be to identify activity centers and activities. For example the cost of running the cafeteria in any institution may include many direct costs such as food, equipment, cooks and service personnel. First the data on directly related costs should be accumulated for the activity center to be examined. The next step would be to chart and determine the relationship of total cost to the underlying activity. For example food costs can be expected to vary directly with the volume of meals served. On the other hand, equipment may have less linear relationship. Labor costs may include fixed and variable components. General administrative overhead should not be ignored. As illustrated in Figure II, a variable cost element may be in addition to the fixed overhead allocation. In this kind of cost chart the variable cost begins above the zero point. Another important step in activity based cost analysis involves the allocation of indirect costs such as administration, physical plant overhead, information technology services. Appropriate allocation basis must be developed for each category of indirect cost as well. They too can be fixed variable or mixed. 


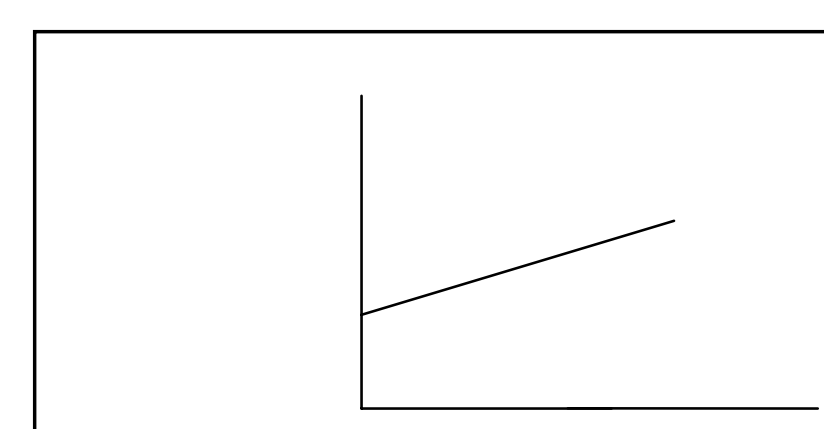

\section{Mixed Cost Diagram}

Figure II Variable Cost Added to Fixed Overhead

\section{CONCLUSION}

Cost behavior analysis is vital to most budgeting and pricing decisions. Of course instantaneous conversion to a new budget model is not recommended. There is a need to first develop a basic understanding of the key components of cost behavior, managerial accounting principles and activity-based cost analysis methodologies. Once the techniques are familiar they can be incorporated into all future areas of decision-making since each area has a financial base. $\mathrm{ABC}$ is not an accounting exercise; it uses accounting data to generate knowledge. This kind of analysis is an important management information tool that allows a director to articulate goals of individual units or programs with respect to the kind and amount of staff, space and materials needed to provide a particular level of service. It could enhance the opportunity to obtain additional budget resources and sell new programs to the town fathers

\section{REFERENCES}

1. Shera, J. 1976. Introduction to Library Science. Littleton, Co: Libraries Unlimited.

2. Taylor, V. A. and C. M. Coughlin. 2000. "Money Always Matters: An Analysis of Cost Behaviors in Libraries Over Time” Proceedings, The Latvian Book and Libraries: 1525-2000, International Conference, Riga , Latvia, 7-10 November 2000. 